\title{
A PATIENT WITH DERMATOMYOSITIS DEVELOPING STEROID INDUCED MYOPATHY: A CASE REPORT
}

\author{
AKTER T ${ }^{1}$, KARIM ME $^{2}$, DAS PP ${ }^{3}$, BISWAS $^{4}$, KABIR AKMH ${ }^{5}$, HAQUER MA ${ }^{6}$, CHAKRABORTY A $^{7}$, \\ ISLAM MA ${ }^{8}$
}

\begin{abstract}
Dermatomyositis is not a very uncommon disease affecting skin and muscles. Some varieties have atypical presentations and early diagnosis is pivotal to the effective management as it has significant morbidity and mortality including malignancy. Corticosteroids and other immunosuppressive is the mainstay of treatment; however, it should also be aimed to reduce the complications of steroid therapy as there is a possibility of steroid induced myopathy where withdrawal of steroid with introduction of other immunosuppressive drug is promptly warranted. Here, we presented a 60 year old lady with dermatomyositis who developed steroid induced myopathy.
\end{abstract}

Key words: Dermatomyositis, steroid induced myopathy.

J Dhaka Med Coll. 2015; 24(2) : 156-159.

\section{Introduction}

Dermatomyositis is a disorder mainly of skin, muscle and blood vessels in which characteristic erythematous and edematous changes in skin are associated with muscle weakness and inflammation ${ }^{1}$. Although exact etiology is unknown, certain factors may predispose to dermatomyositis as well as including some neoplastic condition and paraneoplastic symptoms ${ }^{2,3}$. Along with diagnosis, specific consideration may need to focus on treatment as well as the complication of the disease itself and also on treatment complications e.g. steroid induced myopathy ${ }^{4}$. Myopathy of dermatomyositis and steroid induced myopathy should be distinguished both clinically and histopathologically ${ }^{5}$.

\section{Case history}

A 60 year old lady has presented with a history of generalized bodyache for 3 months and diffuse skin rashes for 1 month. She gradually became lethargic and subsequently developed weakness on walking, standing or even sitting unsupported. She also described a persistent low grade fever for 1 month and new onset diabetes for last 6 months with having no history of hypertension or bronchial asthma.

On examination, there were marked erythematous rashes more noticeable on face and over the knee joint areas without joint involvement and there was periorbital puffiness. Temperature varied from $100-101^{\circ} \mathrm{F}$ throughout the period of hospital admission having no definite pattern. Other vitals were normal. Deep tendon reflexes were difficult to elicit and there's marked degree of muscle tenderness on palpation.

Laboratory investigations revealed dimorphic anaemia with lymphopenia with a raised ESR (115 $\mathrm{mm}$ in $1^{\text {st }}$ hour), markedly elevated muscle enzymes (CPK-17614 u/1), ANA negative, Anti-DsDNA negative, ENA profile negative, serum ferritin-4621ugm/L, blood culture report was unremarkable and x-ray

1. Dr. Taslima Akter, Registrar, Department of Medicine, Dhaka Medical College Hospital, Dhaka.

2. Dr. Md. Enamul Karim, Professor, Department of Medicine, Dhaka Medical College, Dhaka.

3. Dr. Partha Pratim Das, Associate Professor, Department of Medicine, Dhaka Medical College, Dhaka.

4. Dr. Sarmistha Biswas, Assistant Professor, Department of Medicine, Dhaka Medical College, Dhaka.

5. Dr. A.K.M. Humayon Kabir, Assistant Professor, Department of Medicine, Dhaka Medical College, Dhaka.

6. Dr. Mohammad Ahsanul Haque, Assistant Professor, Department of Medicine, Comilla Medical College, Dhaka.

7. Dr. Ashim Chakraborty, Resident Physician, Sir Salimullah Medical College, Dhaka.

8. Dr. Md. Ashraful Islam, Resident, Phase-B, Department of Paediatric Nephrology, Bangabandhu Sheikh Mujib Medical University (BSMMU), Dhaka.

Correspondence: Dr. Taslima Akter, Registrar, Department of Medicine, Dhaka Medical College Hospital, Dhaka. 
skull, x-ray chest and ultrasonogram of abdomen were found normal. Serum basal cortisol, blood urea, serum creatinine, serum calcium were normal and $\mathrm{HBsAg}$, Anti-HCV, VDRL, TPHA were negative.

Finally, muscle biopsy was done and histopathology showed perifascicular atropy, infiltration of inflammatory cells along with necrotic and regenerated muscle fibres with no inclusion bodies suggestive of inflammatory myopathy compatible with dermatomyositis.

Treatment was started with prednisolone $1 \mathrm{mg} /$ $\mathrm{kg}$ body weight along with omeprazole, calcium supplement and indomethacin and there was a substantial improvement in next 10 days. She was then discharged with a follow up advice after 3 months.

On the first follow up, patient could sit unsupported but yet to walking and standing alone. Her skin rashes and muscle pain was reduced, fever subsided and general condition improved.

On subsequent follow up at 6 months of starting treatment, the patient again complaint of significant muscle pain and was unable to sit unsupported. Muscle biopsy was done again and histopathology showed type-2 fibre atropy. A diagnosis of steroid induced myopathy with dermatomyositis was confirmed and methotrexate was started at $10 \mathrm{mg}$ weekly with folic acid and gradual tapering of steroid.

\section{Discussion}

Dermatomyositis (DM) is a form of idiopathic inflammatory myopathy that involves skeletal muscle and skin characterized by the appearance of progressive muscle weakness and inflammation ${ }^{1}$. It is potentially life threatening that affecting individuals of all ages .The estimated incidence of DM has been calculated as 9.63 per 1 million persons, with a prevalence of 21.42 per 100,000 persons .The etiology of dermatomyositis remains unknown; some studies have reported an association with histocompatability antigens, environmental agents (e.g., virus, drugs) and autoimmunity ${ }^{2}$. The average age at diagnosis is 40, and almost twice as many women are affected as men ${ }^{3}$.

\section{Classification:}

Dermatomyositis has been classified in different ways. A practical approach is to divide it into adult-onset and juvenile-onset each being further divided into subgroups:

\section{Adult onset}

- Classic dermatomyositis alone

- Classic dermatomyositis with malignancy

- Classic dermatomyositis of an overlap connective tissue disorder

- Amyopathic dermatomyositis

\section{Juvenile onset}

- Classic dermatomyositis

- Amyopathic dermatomyositis

- Hypomyopathic dermatomyositis ${ }^{6}$.

The muscle involvement is typically defined as slowly progressive, symmetrical proximal muscle weakness in the presence of elevated muscle derived enzymes, abnormal muscle biopsy with MRI or electromyelogram (EMG). Patients complain of fatigue of muscles or weakness while climbing stairs. There is also difficulty in rising from sitting position, combing hair and reaching for items above the shoulders. Muscle tenderness is a variable finding. Testing of muscle strength is part of assessment of these patients. Extensor muscles are more affected than flexors. Distal strength is almost always maintained ${ }^{7,8}$.

Cutaneous features may present simultaneously or may follow or preceed muscle involvent. It includes pathognomic changes of heliotrope rashes and gottron's papule as well as characteristics photosensitive erythema, non-scarring alopecia with or without scaly poikilodermatous changes and subungual or cuticular changes ${ }^{9}$. Systemic features of dermatomyositis include arthralgia, arthritis, dyspnea, dysphagia, dysphonia, arrhythmias, abdominal pain and visual changes ${ }^{9}$.

\section{Diagnostic criteria for dermatomyositis:}

1. Skin lesions

i. Heliotrope rash

ii. Gottron's sign

iii. Erythema on the extensor surface of extremity joints, slight raised red-purple erythema over elbows or knees 
2. Proximal muscle weakness

3. Elevated serum creatine kinase or aldolase level

4. Muscle pain on grasping or spontaneous pain

5. Myogenic changes on electromyography

6. Positive anti-Jo-1 antibody test

7. Nondestructive arthritis or arthralgia

8. Systemic inflammatory signs such as temperature more than $37^{\circ} \mathrm{C}\left[98.6^{\circ} \mathrm{F}\right]$ at axilla, elevated serum $\mathrm{C}$-reactive protein level or ESR of more than $20 \mathrm{~mm}$ per hour.

9. Pathological findings compatible with inflammatory myositis.

Patients presenting with at least 1 finding from the above three and 4 findings from features 2-9 are said to have dermatomyositis ${ }^{10,11}$.

Complications of dermatomyositis include contracted limbs, aspiration pneumonia, type II respiratory failure, diffuse interstitial pneumonitis, pulmonary fibrosis, pericarditis, cardiac failure, cardiomyopathy, cardiac conduction defects, vasculitis, large bowel infarction (secondary to vasculopathy), muscle atrophy, muscle calcification, malnutrition, acute kidney failure, malignancy, Raynaud's phenomenon, hypertrichosis and sclerosis of skin. Ocular complications include nystagmus, cotton-wool spots, optic atrophy and conjunctival edema $^{10,11}$.

Dermatomyositis precedes the neoplasm in $40 \%$ cases, may present simultaneously in $26 \%$ cases and neoplasm may occur first in 34\% cases. Primary tumour occurs in lungs, breast, female genital tract, stomach, rectum, kidney or testis ${ }^{12}$.

\section{Investigations:}

Laboratory investigations is pivotal for confirmation of a diagnosis of dermatomyositis along with pertinent clinical components as elevated muscle enzyme and characteristic histopathologic findings are important part of diagnosis, e. g.

1. Muscle enzyme elevation (CPK, serum aldolase, LDH, ALT, AST, carbonic anhydrase isoenzyme II)
2. EMG: There is myopathic pattern, $10 \%$ are false-negative.

3. Muscle biopsy shows necrotic and regenerative muscle fibre with inflammatory cell infiltrate (Fig. 1)

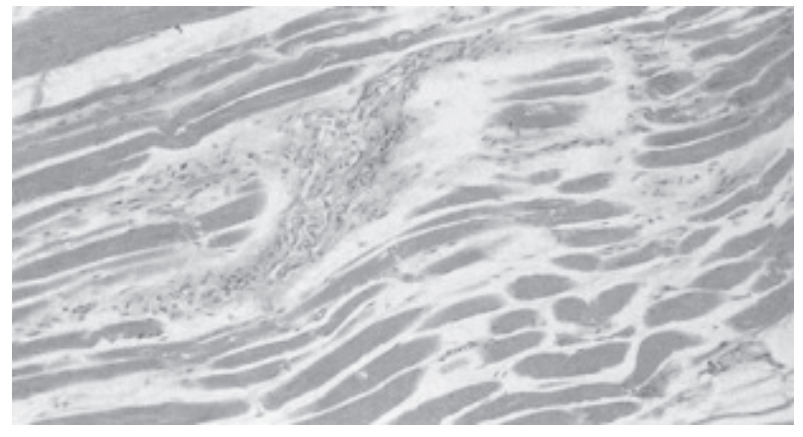

Fig.-1: Degeneration of muscle bundles with edema and inflammatory cells.

4. Autoantibodies:

i. ANA levels elevated in 60 to $80 \%$ of patients with classic dermatomyositis,

ii. Anti-Jo-1 most common antisynthetase found; $20 \%$ of patients with dermatomyositis may have positive result,

iii. Anti-EJ may be more associated with typical skin lesions.

5. ESR is elevated in approximately $50 \%$ patients (does not correlate well with disease activity).

6. Rheumatoid factor seen in $20 \%$ patients, mostly in those with overlap syndrome.

7. von Willebrand factor reported to correlate with juvenile dermatomyositis.

8. Magnetic resonance imaging is useful for assessing the presence of an inflammatory myopathy in patients without weakness. Also useful in differentiating steroid myopathy from continued inflammation and may serve as a guide in selecting a muscle biopsy site ${ }^{10}$.

\section{Treatment:}

Prednisone remains the initial oral pharmacologic agent, given in a single daily dose of 0.5 to $1.5 \mathrm{mg}$ per $\mathrm{kg}$ until the serum creatine kinase (CK) level is normalized and then slowly tapered over the following 12 
months. An alternate regimen is 40 to $60 \mathrm{mg}$ of prednisone per day ( 1 to $2 \mathrm{mg}$ per $\mathrm{kg}$ in children) in divided doses until the CK level has normalized. If the CK level remains within normal limits, that dose may be reduced by one fourth every three to four weeks. Prednisone should continue to be tapered until a maintenance dosage of 5 to $10 \mathrm{mg}$ per day is reached. If no improvement in objective muscle strength occurs after three months of prednisone therapy, other immunosuppressive therapy should be considered which may be necessary in approximately 25 percent of patients ${ }^{3}$.

Methotrexate is considered the first-line adjuvant therapy in patients who do not respond to prednisone. Oral therapy should be initiated at a dosage of 7.5 to $10 \mathrm{mg}$ per week and increased by $2.5-\mathrm{mg}$ increments until a goal of $25 \mathrm{mg}$ per week is reached. Alternate intravenous dosing initiated at $10 \mathrm{mg}$ per week should be increased by $2.5 \mathrm{mg}$ per week until a total dosage of 0.5 to $0.8 \mathrm{mg}$ per $\mathrm{kg}$ is reached. It is important to also give 1 to $3 \mathrm{mg}$ per day of folic acid to minimize the side effects of methotrexate 3,13 .

Azathioprine, cyclosporine are suitable alternative or adjuvants in selected cases. Cyclophosphamide and IV immunoglobulin can be used in refractory cases. Other therapies include physical therapy, antihistamine for pruritus while thymectomy, plasmapheresis and ACTH gel are under trial ${ }^{13}$.

It is important to be aware of steroid myopathy which may mimic a worsening dermatomyositis. Differentiating steroid myopathy from worsening dermatomyositis is based on evaluation of neck flexor strength - neck flexor strength would be unchanged if steroid myopathy were developing. In these cases, methotrexate should be the choice where steroid should be gradually tapered and withdrawn ${ }^{3}$.

\section{References}

1. Bendewald MJ, Wetter DA, Li X, Davis MDP. Incidence of dermatomyositis and clinically amyopathic dermatomyositis: a population-based study in Olmsted County, Minnesota. Arch Dermatol 2010; 146(1): 26-30.

2. Callen JP. Dermatomyositis. In: Callen JP, ed. Dermatological signs of internal disease. $2^{\text {nd }}$ ed. New York: Saunders; 1995: p.13-20.

3. Drake LA, Dinehart SM, Farmer ER, Goltz RW, Graham GF, Hordinsky MK, et al. Guidelines of care for dermatomyositis. American Academy of Dermatology. J Am Acad Dermatol 1996; 34(5 pt 1): 824-9.

4. Cushing $\mathrm{H}$. The basophil adenoma of the pituitary body and their clinical manifestation. Johns Hopkins Med J 1932; 50: 137

5. Pereira RM, Freire de Carvalho J. Glucocorticoidinduced myopathy. Joint Bone Spine 2011; 78: 41-4.

6. Wolff K, Johnson RA, Suurmond D. Skin signs of immune, autoimmune and rheumatic diseases. Fitzpatrick's Color Atlas and Synopsis of Clinical Dermatology, $5^{\text {th }}$ edition. New York: McGraw-Hill; 2005. p. 356-439.

7. Callen JP, Wortmann RL. Dermatomyositis. Clin Dermatol 2006; 24: 363-73.

8. Sontheimer RD. Skin manifestations of systemic autoimmune connective tissue disease: diagnostics and therapeutics. Best Pract Res Clin Rheumatol 2004; 18: 429-62.

9. Callen JP. Dermatomyositis. Lancet 2000; 355(9197): 53-7.

10. Sontheimer RD. Dermatomyositis. In: Freedberg IM, Eisen AZ, Wolff K, et al., eds. Fitzpatrick's dermatology in general medicine. $5^{\text {th }}$ ed. New York: McGraw-Hill; 1999: p.2009-20.

11. Kovacs SO, Kovacs SC. Dermatomyositis. J Am Acad Dermatol 1998; 39: 899-920.

12. Savin JA. The skin and systemic disease-genetics and skin disease. In: Buxton PK. ed. ABC of dermatology. $4^{\text {th }}$ ed. London: BMJ Publishing Group; 2003: p.72-81.

13. Dalakas MC, Illa I, Dambrosia JM, Soueidan SA, Stein DP, Otero C, et al. A controlled trial of high dose intravenous immune globulin infusions as treatment for dermatomyositis. N Engl J Med 1993; 329: 1993-2000. 